\title{
Risk Factors for Alloimmunisation in the General Patient Population
}

\author{
S. Eccles,1,2 P. Crispin,1,3 T. Vanniasinkam,2. \\ 1: ACT Pathology, The Canberra Hospital, Canberra \\ 2: Charles Sturt University, Wagga Wagga \\ 3: Australian National University, Canberra
}

\section{Abstract}

For hospitals providing services to regional populations, difficulties are associated with transferred patients with poorly communicated medical history and a risk of alloimmunisation. Identification of patients at risk would assist in planning. A retrospective study of alloimmunised patients was undertaken, comparing the demographics and diagnoses of this population with a control patient population. A preponderance of diagnoses of Sepsis, Haematological Malignancy, GIT Bleeds and Renal Failure was demonstrated in the alloimmunised population. Consistant with prior studies, $\mathrm{RhD}$ negative patients and female patients were over-represented in the study group, which was also on average significantly older .

Keywords: Transfusion, alloimmunisation, red cell antibody.

\section{$\underline{\text { Body }}$}

\section{Introduction}

Our institution is a tertiary referral hospital and major trauma centre and regularly treats patients referred from other hospitals and regions, as well as traumas from a wide catchment area. These patients may have been treated in other institutions, including receiving allogeneic blood transfusions, and are therefore potentially at risk of previous alloimmunisation.

A challenging aspect of these patients is that they may arrive with minimal medical history available, and the history of prior blood exposure is often unclear. Preoperative transfusion serology testing is regularly performed, often on the morning of the surgery, leaving little time to source antigen negative blood if alloantibodies are found. Both the trauma and preoperative scenario present situations where discovering that the patient has an alloantibody at the time of treatment can be particularly problematic.

Due to the nature of the patient population it was considered advantageous to be able to 'profile' the patient who was at high risk of having already been alloimmunised following red cell exposure. This would then provide an advanced warning of potentially high risk patients and, where possible, enable us to perform their transfusion serology testing earlier in order to allow for the detection and identification of these antibodies and the provision of suitable blood products.

\section{Materials and Methods}




\subsection{Patient Database}

A retrospective study was undertaken on patients in whom red cell alloantibodies were detected serologically by ACT Pathology Transfusion Laboratories from 2008 to 2011. A patient control group consisting of the total patients tested by the ACT Pathology Transfusion Laboratories in 2008 was used. Patient records were extracted from the Kestral Laboratory Information System using an existing data extraction for red cell antibodies, and additional information including the blood group and diagnosis was retrieved on a patient by patient basis. Diagnoses were drawn from the clinical notes supplied to ACT Pathology.

Patients with proven prophylactic Anti-D were removed from the database, as were those with auto-antibodies and those whose antibodies had no definable specificity or were proven on further investigation to be cross-reacting white cell antibodies. The data was then deidentified, with only the patient's sex and year of birth being retained. This yielded a database of 589 alloimmunised patients and 12246 control patients.

\subsection{Statistical analysis}

Multivariate analyses for gender, ABO Blood Group, $\mathrm{RhD}$ status and diagnosis were performed using the Pearson's Chi-square test. The mean and standard deviation of the age distribution of both patient groups were analysed using the Unpaired T Test. All analyses were calculated using GraphPad InStat software. $P$ of less than or equal to 0.05 was considered statistically significant.

\section{Results}

The initial data extraction yielded 589 patients who presented to the ACT Pathology Transfusion Laboratories with red cell alloantibodies between 2008 and 2011. These patients' full transfusion histories were further examined and 362 patients (61.4\%) proved to have had antibodies detected on their initial presentation to the laboratories (which may have predated the investigative time frame) and thus had been transfused elsewhere.

Of the 227 (38.6\%) patients who initially presented without antibodies and were found on a later date to have become alloimmunised, 15 had neither a history of transfusion nor pregnancy as per ACT Pathology records. These patients had a mean of 5.28 years between their last negative antibody screen and their first positive one, indicating that they were likely to have received treatment elsewhere in the intervening years. It is the lack of this comprehensive treatment record that makes treating these patients particularly challenging.

\section{[Table 1]}

[Table 2]

The patient and control databases were analysed for the ratios of male to female patients, ABO blood group and RhD status (Table 1). Analysis of the diagnoses of patients within both groups revealed an array of presentations, which have been broadly categorised (Table 2).

There was a significantly higher proportion of females $(P<0.001)$ in the alloimmunised population than in the control population. The alloimmunised patients were also significantly older, there being a difference between the means of 8.41yrs $(P<0.001)$. 
ABO status did not vary significantly between the alloimmunised patients and the control patients $(P=0.54)$ however there was a significantly higher proportion of RhD Negative individuals in the alloimmunised group $(P<0.001)$.

The array of diagnoses were significantly different between the alloimmunised and control populations. The diagnoses of GIT Bleed, Haematological Malignancy, Renal Failure and Sepsis were all significantly higher in the alloimmunised population. Pregnancy was significantly under-represented in our alloimmunised population, an unexpected result. Diagnoses given but not otherwise listed were categorised as Other and were significantly lower, with only 21 patients in the alloimmunised group falling into that category. Other diagnostic categories did not show significantly different proportions within the populations.

[Figure 1]

[Figure 2]

There was a distinct difference in age distribution between male and female patients in both the control and alloimmunised populations. Both groups show a peak amongst female patients of child-bearing age (Fig.2) which is clearly not present in male patients of similar ages (Fig.1), accounted for by the hospital's function as an obstetric centre. Importantly for this study, both groups show a peak around the 70-90 years range.

The entire tested population was extracted for 2008 as a control, the alloimmunised population for 2008-2011. Total patient numbers through the laboratory for the period 20082011 were 58480. Based upon the data analysed, this gives an overall alloimmunsation rate amongst tested patients of $1.0 \%$.

\section{Discussion}

The alloimmunised patient presents an added level of complexity in the transfusion situation, the unexpected alloimmunised patient even more so. Antigen negative red cells are required and, depending on the specificity of the antibody or antibodies present, matched blood may be difficult to source. Donor red cells must then be cross-matched using an Indirect Antiglobulin Technique which can further slow down the process, hindering access to what blood is available. Thus, greater preparation time for the provision of blood products should be allowed for patients with known red cell antibodies prior to events that may require transfusion.

Amongst the 589 alloimmunised patients in this study, the diagnoses of GIT Bleed, Haematological Malignancy, Renal Failure and Sepsis were over-represented when compared with the control group. The first three diagnoses are directly associated with high levels of red blood cell transfusion. Sepsis is an acute diagnosis and not directly associated with red cell usage however it is more common following complex surgery or trauma, which are in turn situations which often involve high levels of blood use. A search of the literature did not reveal any other studies linking Sepsis with alloimmunisation.

Alloimmunisation results primarily from exposure to immunogenic red cells through either transfusion or pregnancy, [1] and the greater the exposure, the greater the risk of the patient 
having an immune response [2]. Therefore it is reasonable to deduce from the data that the higher usage of donor red cells in these diagnoses is directly linked to the higher rate of red cell antibody production. This compares with the findings of Koelewijn et al [3] whose study of pregnant women found that previous pregnancy, surgery and history of transfusion were significant risk factors for alloimmunisation. Steigler et al [4] also reported a high rate of alloimmunisation amongst patients with MDS and Renal failure.

Female patients were found to be significantly over-represented in the alloimmunised population. If we assume a previous history of pregnancy amongst a proportion of female patients and therefore a corresponding rate of foetal red cell exposure, we can explain the higher rate of alloimmunised females amongst the patients studied. Whilst the introduction of Anti-D prophylaxis has reduced the rate of $\mathrm{RhD}$ alloimmunisations, it does not prevent it entirely, nor prevent the production of other antibodies during pregnancy [5]. Interestingly, Verduin et all [6] report a greater long-term persistence of foetal-induced red cell antibodies compared to transfusion induced alloimmunisation.

Issitt and Anstee [7] estimated that the rate of presentation with a clinically significant red cell antibody was approximately $1 \%$ to $1.5 \%$ amongst patients and $0.2 \%$ amongst healthy blood donors. This is comparable with this study's estimated overall alloimmunisation rate of $1.2 \%$ for the period of 2008-2011. This is the rate across all patients encountered by the transfusion service. It is interesting to note that a large study in Hungary [8] found an alloimmunisation rate of $6.16 \%$ in the general patient population when the screening method included an enzyme technique to enhance detection of weak alloantibodies with enzymeenhanced specificities. The value of the detection of enzyme-only antibodies has been hotly debated in the literature, as the clinical significance of 'enzyme only' antibodies is dubious.

The rate of red blood cell alloimmunisation varies greatly between studies and can be as high as $60 \%$ in patients transfused on a chronic basis [9]. Other studies report more modest rates; 8.4\% following transfusion during elective surgery [10], 6.1\% amongst transfused patients in Uganda [11] and 7.9\% amongst patients awaiting a liver transplant in the UK [12]. A study of chronically transfused thalassaemic patients found an alloimmunisation rate of $11.8 \%$.[13] Given the nature of the study cohort and the initial problem of incomplete medical and transfusion histories across multiple sites, it was not possible to accurately assess each patient's total blood unit exposure. This would have been interesting data to compare with the alloimmunisation rates but if available would render the study unnecessary.

Whilst the patients' ABO blood group did not differ significantly, the RhD status of the patient was found to be important in determining the likelihood of previous alloimmunisation, with RhD negative individuals significantly more likely to have red cell antibodies. $\mathrm{RhD}$ is recognised as the most immunogenic and clinically important red cell antigen after the ABO antigens, and is why it is routinely included in blood group testing [14].

It was estimated by Klein and Anstee [1] that $85 \%$ of RhD negative individuals will produce an anti-D following transfusion with $200 \mathrm{mLs}$ of $\mathrm{RhD}$ positive blood. However a study by Yazer and Triulzi [15] found that of $98 \mathrm{RhD}$ negative patients transfused with RhD positive blood, only 22 (22\%) produced anti-D antibodies. Cerdas-Quesada [16] reported that 75\% of antibodies produced by their study cohort were Rh antibodies. It is interesting to note that Yazer and Triulzi [15] report that within their sub-cohort that received only leukodepleted red 
blood cells, the $\mathrm{RhD}$ alloimmunisation rate dropped to $13 \%$. Their lower reported rate of overall alloimmunisation may be due to increasing rates of leukodepletion and other improvements in packed red cell manufacturing. Following the introduction of Anti-D prophylaxis, the rate of $\mathrm{RhD}$ alloimmunisation in pregnancy is dropping, whilst the relative frequency of non-rhesus antibodies is rising [17].

The aging patient population requires a greater number of surgical procedures [18] and thus the older the patient the greater the probability that they have had a pregnancy or procedure that involved blood transfusion and thus exposure to red cell antigens. This is reflected in this study where the alloimmunised population shows a mean age increase of 8.49 years over the control population, presumably due to greater exposure through surgery or pregnancy and resulting risk of formation of antibodies. An elegant contrast is provided by the low incidence $(0.05 \%)$ of alloantibodies in the healthy blood donor cohort studied by Pahuja et al [19] where $98.6 \%$ of the cohort was male and a large proportion were under 30 years of age.

The diagnoses of GIT Bleed, Haematological Malignancy, Renal Failure and Sepsis are found in higher frequencies in the alloimmunised patient population, along with female sex, increased age and more frequent $\mathrm{RhD}$ negative status. From this we can hypothesise that a history of these diagnoses and possession of any of these demographics would be suggestive of a higher risk of a particular patient having already formed a red cell alloantibody, which would be of particular importance in the pre-operative setting. The alloimmunisation risk of these patients may be considerably higher than the $1.5 \%$ chance of alloimmunisation observed in the total patient population [7].

Whilst the RhD status will only be known following serological testing, the age, sex and diagnosis of the patient are immediately available. These indicators allow the surgeon to organise the patient's pre-admission plan to accommodate the process of finding antigen negative blood, and in the unfortunate event of a trauma, alerts the trauma team to the possibility of an alloimmunised patient. It presents an excellent opportunity for the treating team to provide the best level of care, and avoid the situation of the patient being in surgery only to have the Transfusion Laboratory phone to report that they have a red cell antibody and blood will take several hours to provide. First and foremost in prevention of this scenario is always a review of the patient's history for any previously detected alloantibodies.

\section{Conclusions}

Several important observations can be made from the data which have potential implications for patient care, particularly in the situation where patients arrive at a health care institution particularly one with a large patient catchment and referral area - with minimal available medical history. In this study, the alloimmunised patient population showed an overrepresentation of GIT bleeding, haematological malignancy, renal failure and sepsis. A patient history of any of these diagnoses should be considered a risk factor for previous alloimmunisation in the presenting patient. Female patients, older patients and patients who are RhD Negative were also over-represented when compared to the control patient group.

Whilst the patient's RhD type is only available once the transfusion service has processed the patient' sample, the patient's sex, approximate age and immediate diagnosis are able upon presentation. Using the demographics and diagnoses identified in this study, patients could be triaged as being at low or high risk of previous alloimmunisation and treated accordingly. 


\section{Acknowledgements}

The author would like to acknowledge the work of the staff of the ACT Pathology Transfusion Laboratories.

\section{Conflict of interest}

The researcher has no conflict of interest to declare.

\section{References}

1. Klein, H. \& Anstee, D. (2005) Blood transfusion in clinical medicine $\left(11^{\text {th }}\right.$ Ed). Oxford (UK), Blackwell Publishing.

2. Abdel Galil M., Abdel G., Abeer K., Al Ghumlas, Abdel Kareem M. A. Transfusion medicine in a developing country - Alloantibodies to red blood cells in multitransfused patients in Saudi Arabia. Transfusion and Apheresis Science Volume 39, Issue 3, December 2008, Pages 199-204

3. Koelewijn, J., Vrijkotte, T., de Haas, M., van der Schoot, C. \& Bonsel, G. (2009) Risk factors for the presence of non-rhesus $\mathrm{D}$ red blood cell antibodies in pregnancy. BJOG 2009;116:655-664.

4. Stiegler, G., Sperr, W., Lorber, C., Fabrizii, V., Höcker, V., Panzer, S. Red cell antibodies in frequently transfused patients with myelodysplastic syndrome. Ann Hematol (2001) 80:330-333

5. Moise, K. Red Blood Cell Alloimmunization in Pregnancy. Seminars in Haematology. Division of Maternal-Fetal Medicine, University of North Carolina School of Medicine, Chapel Hill, NC. (2005)

6. Verduin, E., Schonewille, H., Lindenburg, I., Lopriore, E., Oepkes, D., Doxiadis, I., Branda, A. Fetal induced red blood cell antibodies persist over 20 years. Journal of Reproductive Immunology 86 (2010) 79-111

7. Issitt, P. \& Anstee, D. (1998) Applied Blood Group Serology ( $4^{\text {th }}$ Ed). Durham (NC), Mongomery Scientific Publications.

8. Gazdag, E., Jakab, J., Zsigmond-So'os, I., Gol'acs, N., Benk"o, S., Vagner, M, Krist'ofi, Ns., Bedekovich. N. Frequency of red blood cell antibodies in adult patients. Oral presentations, ISH EAD 2007, Budapest, Hungary, 29 August 2 September 2007.

9. Schonewille, H., van der Watering, L., Brand, A. (2006). Additional red blood cell alloantibodies after blood transfusion in nonhaematologic alloimmunised patient cohort: is it time to take precautionary measures? Transfusion 2006: col 46, pp 630635.

10. Redman, M., Regan, F., Contreras, M. (1996). A prospective study of the incidence of red cell allo-immunisation following transfusion. Vox Sanguinis Vol 71, pp 216-220.

11. Natukunda, B., Schonewille, H., van de Watering, L., \& Brand, A. (2010). Prevalence and specificities of red blood cell alloantibodies in transfused Ugandans with different diseases. Vox Sanguinis, 98(2), 167-171. Retrieved from MEDLINE with Full Text database.

12. Mushkbar, M., Watkins, E. \& Doughty, H. A UK single-centre survey of red cell antibodies in adult patients undergoing liver transplantation. Vox Sanguinis (2013) 105, 341-345 
13. Azarkeivan, A., Ahmadi, M., Gharebaghian, A., Nasizadeh, S., Zolfaghari, S., Maghsoodlu, M., Ayoub, M. RBC alloimmunization in chronic transfusion patients (thalassemics) Posters, ISH EAD 2007, Budapest, Hungary, 29 August 2 September 2007.

14. Poole, J. \& Daniels, G. Blood Group Antibodies and Their Significance in Transfusion Medicine. (2007) Transfusion Medicine Reviews, vol 21, pp58-71.

15. Yazer, M. \& Triulzi, D. (2007) Detection of anti-D in D- recipients transfused with D+ red blood cells. Transfusion, vol 47, pp 2197-2201.

16. Cerdas-Quesada, C. Specificity of 136 patient's antibodies to human red blood cells in Dr. Max Peralta J Hospital Blood Bank 2004-February 2009. Transfusion and Apheresis Science 42 (2010) 105-108

17. Moise K. Non-anti-D antibodies in red-cell alloimmunization. Eur J Obstet Gynecol Reprod Biol. 2000 Sep;92(1):75-81.

18. Etzioni, D., Liu, J., Maggard, M. \& Ko, C. The Aging Population and Its Impact on the Surgery Workforce. Annals of Surgery, Volume 238, Number 2, August 2003

19. Pahuja S., Kushwaha S., Sethi N., Pujani M. \& Jain M. Screening of blood donors for erythrocyte alloantibodies. Hematology. 2012 Sep; Vol. 17 (5), pp. 302-5.

\begin{tabular}{|c|c|c|c|c|c|}
\hline \multirow{2}{*}{ Sex } & \multicolumn{2}{|c|}{$\begin{array}{l}\text { Control Patients } \\
\mathrm{N}=12246\end{array}$} & \multicolumn{2}{|c|}{$\begin{array}{l}\text { Alloimmunised } \\
\text { Patients } n=589\end{array}$} & \multirow{2}{*}{$\begin{array}{l}P \text { Value } \\
<0.001 \\
\end{array}$} \\
\hline & & $\%$ & & $\%$ & \\
\hline Male & 3868 & 31.55 & 139 & 23.60 & \\
\hline Female & 8376 & 68.31 & 450 & 76.40 & \\
\hline \multicolumn{6}{|c|}{ ABO Blood Group } \\
\hline $\mathrm{O}$ & 5598 & 45.66 & 265 & 44.99 & 0.54 \\
\hline $\mathrm{A}$ & 4745 & 38.70 & 222 & 37.69 & \\
\hline $\mathrm{B}$ & 1459 & 11.90 & 74 & 12.56 & \\
\hline $\mathrm{AB}$ & 451 & 3.68 & 28 & 4.75 & \\
\hline \multicolumn{6}{|l|}{ RhD Status } \\
\hline RhD Positive & 10222 & 83.37 & 425 & 72.16 & $<0.001$ \\
\hline RhD Negative & 2031 & 16.56 & 164 & 27.84 & \\
\hline Age Mean & 49.95 & & 58.44 & & $<0.001$ \\
\hline Age SD & 22.24 & & 22.45 & & \\
\hline
\end{tabular}

Table 1. Demographic Results.

\begin{tabular}{|l|l|l|l|l|l|}
\hline Diagnosis & & $\%$ & & $\%$ & $<0.001$ \\
\hline Bleeding & 379 & 3.09 & 14 & 2.38 & 0.322 \\
\hline GIT Bleed & 434 & 3.54 & 41 & 6.96 & $<0.001$ \\
\hline $\begin{array}{l}\text { Haematological } \\
\text { Malignancy }\end{array}$ & 264 & 2.15 & 34 & 5.77 & $<0.001$ \\
\hline Other & 1668 & 13.60 & 21 & 3.57 & $<0.001$ \\
\hline Other Malignancy & 382 & 3.12 & 30 & 5.09 & 0.059 \\
\hline Pregnancy & 4381 & 35.73 & 162 & 27.50 & $<0.001$ \\
\hline Renal Failure & 164 & 1.34 & 20 & 3.4 & $<0.001$ \\
\hline Sepsis & 136 & 1.11 & 27 & 4.58 & $<0.001$ \\
\hline
\end{tabular}




\begin{tabular}{|l|l|l|l|l|l|}
\hline Surgery & 3021 & 24.64 & 167 & 28.35 & 0.036 \\
\hline Trauma & 907 & 7.40 & 50 & 8.49 & 0.312 \\
\hline Unknown & 493 & 4.02 & 23 & 3.90 & 0.886 \\
\hline
\end{tabular}

Table 2. Diagnosis Results

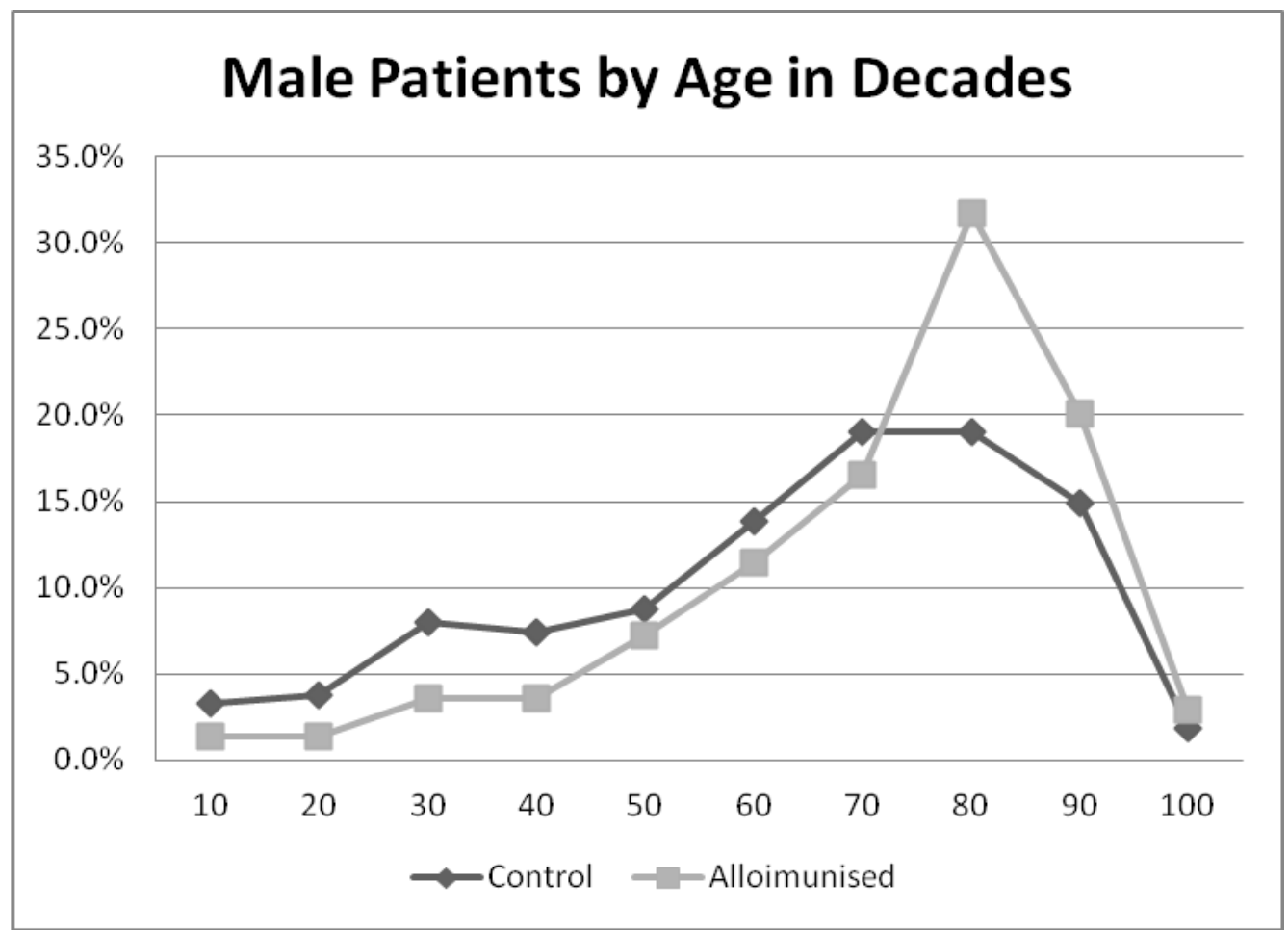

Figure 1. Male patients in age by decades

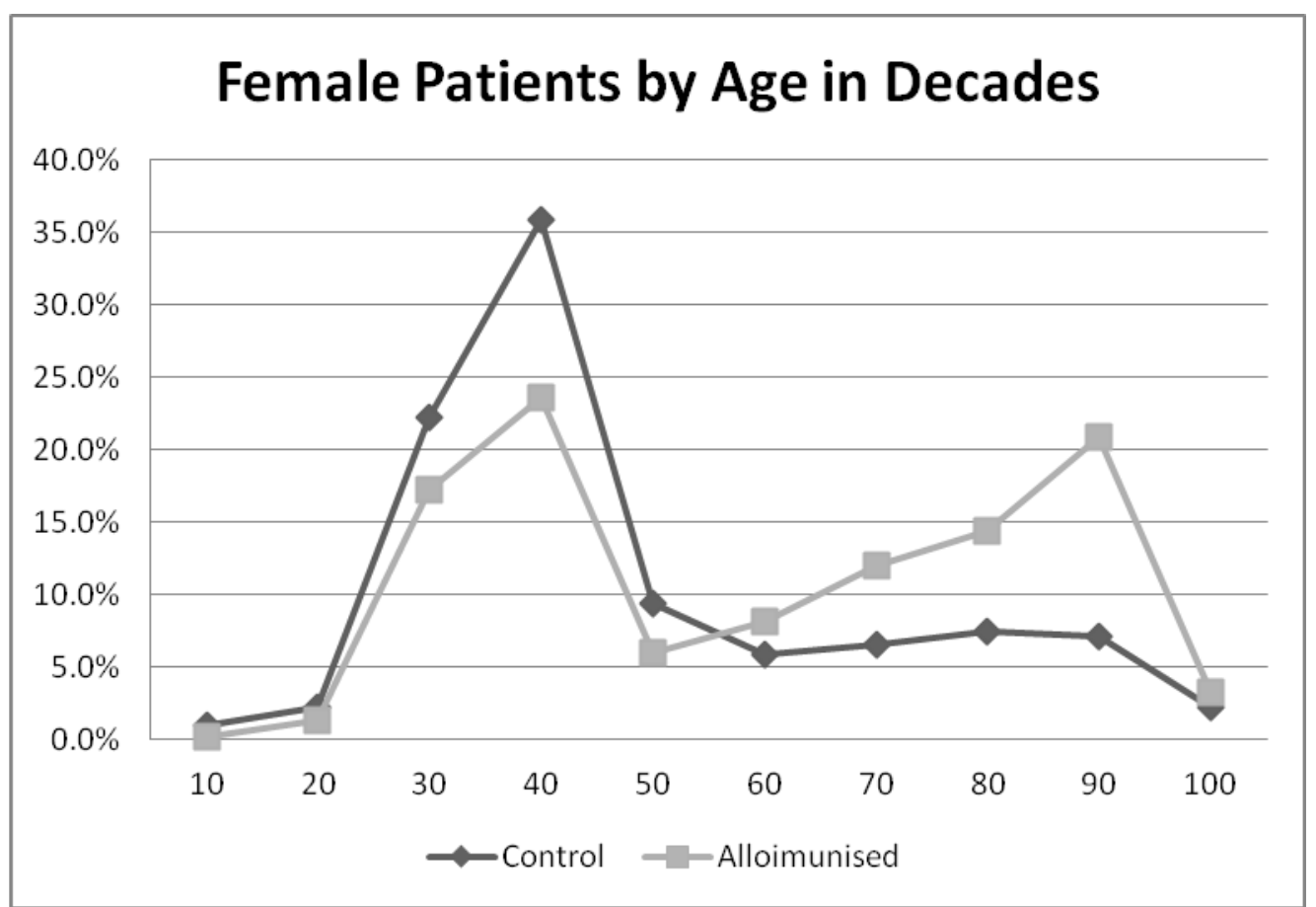

Figure 2. Female patients in age by decades 
Corresponding author: Sarah Eccles. Level 2 Building 10, The Canberra Hospital. Garran, ACT, 2605, Australia. Email: sarah.eccles@act.gov.au Phone: +61 262444239 